\title{
ARTí́CULO
}

\section{EL ESFUERZO EN RESPONSABILIDAD SOCIAL Y SU COMUNICACIÓN EN INTERNET: EL CASO DE LAS EMPRESAS DEL FORO DE MARCAS RENOMBRADAS ESPAÑOLAS}

\author{
Aguirre, $\mathrm{M}^{\mathrm{a}}$ Soledad \\ Aldamiz-echevarría, Covadonga \\ Baelo, Luis $\mathrm{M}^{\mathrm{a}}$ \\ Universidad del País Vasco-Euskal Herriko Unibertsitatea \\ marisol.aquirre@ehu.es \\ covadonga.aldamiz@ehu.es \\ luisbaelo@hotmail.com \\ https://doi.org/10.17979/redma.2009.01.01.4670
}

\section{M ${ }^{a}$ Soledad Aguirre García}

Doctora en CC. Económicas y Empresariales y profesora titular de la Universidad del País Vasco - Euskal Herriko Unibertsitatea donde imparte clases de Marketing Avanzado y Marketing sectorial/Extensiones del Marketing, tanto en grado como en postgrados diversos. Directora del Master en Marketing Executive de la Universidad del País Vasco ${ }^{1}$. Autora de múltiples artículos y ponencias en diversos congresos sobre Marketing Industrial, Marketing Relacional, y Marketing Ecológico fundamentalmente. Coordinadora y coautora del libro titulado Marketing en Sectores Específicos, editado por Pirámide y coautora de La competitividad de las empresas industriales vascas: situación, perspectivas y factores determinantes ${ }^{2}$ editado en 2007.

\section{Covadonga Aldamiz-Echevarria Gonzalez De Durana,}

Doctora en CC. Económicas y Empresariales y profesora titular de la Universidad del País Vasco - Euskal Herriko Unibertsitatea donde imparte clases de Dirección Comercial y de Marketing Internacional tanto en cursos de grado como de postgrado. Entre sus publicaciones destaca su libro titulado Marketing en ONGs de desarrollo, lepala, 2003; así como diferentes capítulos de libros, artículos y ponencias en diversos congresos nacionales e internacionales. Muchos de estas publicaciones pertenecen al área social y medioambiental. Asimismo participa en diversos proyectos de investigación acerca de empresas familiares y género.

\footnotetext{
${ }^{1}$ http://www.ieae.ehu.es/p279content/es/contenidos/informacion/ieae master marketing/es marketin/presentacion.html

${ }^{2}$ http://www.ieae.ehu.es/p279-

content/eu/contenidos/informacion/ieae publicaciones/eu publicac/adjuntos/Competitividad empresas.pdf REDMARKA - Revista Académica de Marketing Aplicado - CIECID - Universidad de A Coruña 3 


\section{Luis Baelo García}

Licenciado en Administración y Dirección de Empresas en la Universidad del País Vasco (UPV), Master en Asesoría Fiscal en la Universidad de Deusto, Master de Dirección Comercial y Marketing en la escuela internacional de negocios CEREM Madrid y, actualmente, doctorando del programa de la UPV/EHU, "La empresa ante la globalización: Riesgo y Conocimiento", Profesionalmente, ha sido ponente de Marketing y Comercialización en el Master de Olivicultura de la Universidad de La Rioja (2007/08), director Comercial y Marketing en la empresa Kel Grupo Alimentario, S.L (2006/2007) y jefe de Ventas en Jamones Belako, $\mathrm{S}, \mathrm{L},(2002 / 2006)$ 


\section{Resumen}

En este trabajo, tras un estudio de la responsabilidad social de la empresa y su relación con la imagen de la misma, se muestran los resultados agregados de un análisis de las páginas web de las 80 empresas que, en marzo de 2008, pertenecían al Foro de Marcas Renombradas Españolas. Aspectos destacables del estudio son que en la web de la mayoría de las empresas existen indicios de llevar a cabo acciones de responsabilidad social, y que, de los tres grupos de acciones analizadas: derechos y condiciones laborales, medio ambiente y vinculación con la sociedad, los que más frecuentemente aparecen reflejados son los relacionados con el Medio Ambiente. Asimismo, en los índices analizados, estas empresas están muy por encima del resto de las empresas españolas.

\section{Palabras clave:}

Responsabilidad Social, Medio Ambiente, Marcas Renombradas

\section{Abstract \\ THE EFFORT IN SOCIAL RESPONSIBILITY AND ITS COMMUNICATION IN THE INTERNET: CASE OF THE SPANISH REPUTATION BRAND FORUM ENTERPRISES}

This paper starts studying the corporate social responsibility's concept and its relationship with the image of the company. The authors have studied corporate web of the 80 companies that, in March, 2008, belonged to the "Foro de Marcas Renombradas Españolas" (that we could translate as the Forum of Spanish Brands with Good Reputation). Prominent aspects of the study are that in the corporate webs of 64 companies, there are indications of carrying out social responsibility actions and that, from the three groups of analyzed actions: rights and working conditions, environment and social activities in general, the ones more frequently turn out to be reflected are the related ones to the Environment. The different indexes analyzed show that these companies are very over other Spanish companies not in the forum.

\section{Keywords:}

Social Responsibility; Environment; Reputation Brands 


\section{PRIMERA PARTE: REVISIÓN TEORICA}

\section{1.-INTRODUCCIÓN}

En este trabajo, pretendemos conocer los esfuerzos en Responsabilidad Social Empresarial (RSE a partir de ahora), realizados por las empresas pertenecientes al FORO DE MARCAS RENOMBRADAS ESPAÑOLAS, a través del análisis del contenido de sus Webs corporativas. Por tanto, estudiaremos más bien el esfuerzo en comunicación de la RSE realizado por estas empresas a en un medio digital concreto: Internet

Este foro, compuesto por 80 organizaciones de muy diversos sectores, está formado por empresas que, además de haber solicitado su inclusión en el mismo, han sido evaluadas favorablemente conforme a parámetros como: reputación, origen español, internacionalización, liderazgo de mercado y tamaño. Entre los objetivos principales del Foro se encuentra el de ser un foro de reflexión y conocimiento sobre la marca, su valor y desarrollo como activo clave para la competitividad.

Todo ello nos lleva a pensar que la gestión de las empresas que pertenecen al mismo, puede ser más profesionalizada e innovadora que la media de empresas españolas y que por tanto pueden ser más proclives a la RSE y a la comunicación del esfuerzo invertido en ella. Además es también posible y razonable pensar que sean empresas más concienciadas que la media con el valor de la marca y de cualquier esfuerzo realizado en su beneficio (incluye esfuerzo de comunicación y por ende de comunicación de la RSE). Del mismo modo, su vocación internacional puede que incida también en su mayor conciencia del valor de tener una buena Web, de actualizar constantemente sus contenidos, de dar señales a través de ella a la comunidad de internautas que es, por definición, internacional. 
Todas esas razones hacen que sean un buen colectivo de empresas a partir del cual extraer conclusiones que nos sirvan para orientar futuros trabajos de investigación.

\section{2.-IMAGEN CORPORATIVA: CONCEPTO Y VALOR}

La imagen, y más especialmente la imagen corporativa, es la percepción y el conjunto de ideas que acerca de una empresa tienen los clientes y en general cada uno de los stakeholders, tanto internos (propietarios, directivos, trabajadores), como externos ya sean clientes, proveedores, sociedad, etc... (Cabeza, Martínez y Fuentes, 2007). Actualmente existe cierto consenso en torno a la idea de que la imagen corporativa, es una construcción mental de los públicos objetivo, generada por la integración de todos los inputs emitidos por una empresa en su relación ordinaria con ellos (Villafañe, 1999).

Es decir, la conformación de estas percepciones e ideas no se deriva a menudo de un conocimiento profundo de la empresa sino que es el fruto de la configuración de una impresión global a partir de los atributos o aspectos de la misma que les son familiares o al menos conocidos. Este efecto halo (Dowling, 1988) explica, entre otras razones, la importancia de la comunicación y el conocimiento (y cuando hablamos de comunicación, nos referimos a todo esfuerzo de comunicación -por tanto también al esfuerzo de comunicación de la responsabilidad Social de la Empresa, RSE- del que hablaremos más adelante).

La importancia estratégica de la imagen corporativa es algo que hoy en día tampoco nadie cuestiona (García de los Salmones, Rodríguez del Bosque, 2005). Muchos trabajos de carácter académico y profesional han desarrollado dicho concepto y analizado sus ventajas, efecto en los públicos y tratamiento por parte de las empresas. En esta línea cada vez son más los tratadistas que afirman, y en algunos casos demuestran que el reconocimiento de las prácticas de RSE parece tener una influencia positiva sobre la imagen y reputación de la empresa, y sobre las actitudes hacia la misma (Fombrun y Shanley, 1990) 


\section{3.-LA RESPONSABILIDAD SOCIAL DE LA EMPRESA (RSE): CONCEPTO Y ANTECEDENTES}

Aunque hay quienes afirman que los antecedentes de la RSE se remontan al siglo XIX en el marco del nacimiento del Cooperativismo (que buscaba conciliar eficacia empresarial con principios sociales de democracia, autoayuda, apoyo a la comunidad y justicia distributiva), las primeras conceptualizaciones de la RSE se desarrollaron en la década de los 50 con trabajos como el de Bowen (1953), considerado por muchos como el origen de la investigación académica sobre el tema. Sin embargo, es durante los años 60 cuando se desarrolla el concepto, basado en la noción de que las corporaciones tienen responsabilidades más allá de sus obligaciones legales (Ramos y Periáñez, 2003).

Tal vez una de las cuestiones que más haya contribuido al desarrollo de la RSE en la última década haya sido la firma del Pacto Mundial de Naciones Unidas $\left(31 /\right.$ enero/1999) ${ }^{3}$; proyecto internacional que incluye una serie de normas o recomendaciones que incorporan un compromiso por parte de los Estados adheridos, para fomentar un desempeño responsable en el entramado empresarial de sus respectivos países. Está orientado difundir, alcanzar, desarrollar y mantener diez principios inspirados en la Declaración Universal de los Derechos Humanos; la Declaración de la Organización Internacional del Trabajo y la Declaración de Río sobre Desarrollo y Medio Ambiente ${ }^{4}$

De todos los modelos conceptuales surgidos para intentar capturar el dominio de la RSE entendemos especialmente interesante para los objetivos del presente trabajo el modelo apoyado en la perspectiva del Desarrollo Sostenible y que se fundamenta en los ejes que componen la triple línea base de la misma, es decir, el económico, el social y el medioambiental (Van Marrewijk, 2003).

\footnotetext{
${ }^{3}$ La organización española que replica el Global Compact puede visitarse en: http://www.pactomundial.org/

${ }^{4}$ El hecho de que una empresa se adhiera al Pacto Mundial de Naciones Unidas, denota a priori que los principios del mencionado Pacto pasan a formar parte de la estrategia, cultura y acciones cotidianas de la misma. REDMARKA - Revista Académica de Marketing Aplicado - CIECID - Universidad de A Coruña 8 Año I, Número 1, (2009), pp. 3-37 
Conforme a este modelo, podemos entender la RSE en los términos expuestos por la Comisión Europea (2001) en el Libro Verde, es decir, como la "integración voluntaria, por parte de las empresas, de las preocupaciones sociales y medioambientales en sus operaciones comerciales y sus relaciones con sus interlocutores. Ser socialmente responsable no significa solamente cumplir a plenitud las obligaciones jurídicas, sino también invertir más en capital humano, el entorno y las relaciones con los interlocutores".

De manera complementaria otros tratadistas se refieren a la RSE como el conjunto de obligaciones y compromisos, legales y éticos, nacionales e internacionales, con los grupos de interés, que se derivan de los impactos que la actividad y operaciones de las organizaciones producen en el ámbito social, laboral, medioambiental y de los derechos humanos. Así por ejemplo, De la Cuesta y Valor (2003), se refieren al "reconocimiento e integración en sus operaciones por parte de las empresas, de las preocupaciones sociales y medioambientales, dando lugar a prácticas empresariales que satisfagan dichas preocupaciones y configuren sus relaciones con sus interlocutores". La empresa es, según ellos, responsable ante todos los que tienen una apuesta (stake) en ella: sus stakeholders ${ }^{5}$.

Decir finalmente que en España, el interés por la responsabilidad social de la empresa es relativamente reciente. En la década de los noventa fue cuando diferentes instituciones públicas y privadas empezaron a preocuparse por esta cuestión, pero quizás el mayor interés por la RSE surgió a finales de los noventa con ocasión del lanzamiento al mercado de productos financieros éticos (fundamentalmente fondos de inversión). No parece, sin embargo, que los consumidores españoles hayan asimilado todavía el concepto de responsabilidad social y tampoco los inversores españoles lo han hecho en la misma medida en que los inversores internacionales; por ello, su presión sobre las empresas es todavía escasa (Ramos, Pueyo, y Llaría, 2004)

\footnotetext{
${ }^{5}$ El término stakeholder se utiliza contraponiéndolo a stockholders o shareholders, los accionistas. Los stakeholders son los grupos o individuos que afectan o son afectados por la actividad de la compañía. 
Sin embargo, la expansión internacional de la empresa española está obligando a nuestras empresas a competir con otras ya preocupadas por su comportamiento sostenible y responsable y ello está favoreciendo la inversión en RSE por parte de estas empresas internacionalizadas (Cuesta et al., 2002; McWilliams, A., et al. 2006). Entre las que se encuentran las del FORO objeto del estudio que aquí presentamos.

\section{4.-EL VALOR DE LA RESPONSABILIDAD SOCIAL DE LA EMPRESA (RSE) EN LA MEJORA DE SU COMPETITIVIDAD}

Como se ha comentado anteriormente, a partir de los noventa la RSE ha ido cobrando fuerza como preocupación política, social e incluso empresarial prioritaria en nuestro entorno. De hecho, son cada vez más los que afirman y demuestran en muchos casos, que las empresas han comenzado a adoptar prácticas de RSE no sólo como resultado de presiones de la sociedad civil, las instituciones públicas, o los consumidores (es decir, todos los conocidos como stakeholders o grupos de interés), sino por razones de competitividad. Así, muchos defienden que la RSE puede ser también una actividad estratégica en la mejora de la competitividad de la empresa y que eso ha llevado también a muchas empresas a comprometerse en la RSE (Moreno, 2004).

Como afirma Moreno, seguramente sea Freeman quien en 1984 formula la primera defensa coherente a la idea de que las preocupaciones centrales de la empresa deben cambiar, frente a los postulados defendidos por el "paradigma liberal" dominante durante los años 70 y 80 (que consideraba que los objetivos sociales y económicos son incompatibles). Freeman defendía que el sostenimiento en el tiempo de los buenos resultados económicos depende de la calidad de la relación de la empresa con muchos sectores (accionistas, clientes, proveedores, empleados, legisladores, agentes creadores de opinión (medios de comunicación, expertos, etc), así como el entorno social en el que opera. Aunque aún falta evidencia empírica suficiente y con el suficiente rigor científico como para demostrar, sin posible controversia, que el comportamiento socialmente responsable sea compatible con la creación de 
valor e incluso, pueda contribuir positivamente a ello, sí hay cada vez más indicios que apuntan en esa dirección.

De hecho, en la actualidad, la mayor parte de las empresas listadas en la lista Fortune 500 describen en su página web sus logros en materia de RSC (Nieto y Fernández, 2004), y casi la mitad de las incluidas en el Fortune 250 elaboran informes específicos sobre aspectos sociales y medioambientales de sus actividades (Bhattacharya, 2003).

También se ha comprobado que las diez empresas más admiradas del mundo según el ranking de PriceWaterhouseCoopers (PWC, 2003) desarrollan prácticas de RSC y las difunden para aprovechar los efectos positivos que genera la transparencia informativa. En nuestro país, se ha producido también un fenómeno similar, así el estudio que viene realizando desde el año 2000 la Fundación Empresa y Sociedad sobre la acción social de las grandes empresas españolas ha puesto también de manifiesto que la mayoría de ellas (muchas de las cuales están también en el FORO que estudiamos en el presente trabajo: BBVA, Endesa, Iberdrola, Iberia, Inditex, etc) informa en sus memorias anuales sobre sus prácticas de RSC (Nieto y Fernández, 2004),.

Por su parte, Diaz de la Hoz, de PriceWaterhouseCoopers (2008), afirmaba en septiembre de 2008, basándose en informes y resultados de estudios realizados por la organización a la que representa y por otras organizaciones de reconocido prestigio (como CSR Europe o McKinsey) cuestiones como las siguientes:

$\checkmark$ Una mayoría significativa de los inversores cree que la gestión del riesgo medioambiental y el riesgo social aumenta el valor de mercado de una empresa a largo plazo.

$\checkmark$ Los inversores institucionales están dispuestos a pagar una bonificación importante en acciones de compañías que muestren Buen Gobierno.

$\checkmark$ Un porcentaje significativo de consumidores castigó o planea castigar a las empresas que no sean vistas como socialmente responsables. 
$\checkmark$ Las empresas más vanguardistas (IBEX 35 y otras) en España reconocen el valor de la RSC para su negocio, pero la gestión es aún incipiente.

$\checkmark$ Una mayoría significativa de las empresas líderes españolas han establecido un Código de Conducta.

Finalmente, en un interesante trabajo de Orlitzky, Schimith y Rynes (2003) en el que se realiza un metanálisis de 52 trabajos de investigación, se confirma una relación positiva entre comportamientos empresariales responsables y resultados económicos. Igualmente se confirma el carácter bidireccional y simultáneo de la causalidad entre ambos comportamientos lo que para los autores sugiere un claro "círculo virtuoso" (Moreno, 2004) que explican del siguiente modo: "las compañías con éxito financiero invierten más en RSE porque pueden permitírselo, pero los comportamientos socialmente responsables también ayudan a lograr mayor éxito económico".

Pese a los estudios mencionados, todavía faltan evidencias suficientes para demostrar sin paliativos que el esfuerzo de estas empresas ha contribuido a su mayor competitividad, mayor valoración por parte de sus accionistas o mayor valoración por parte de sus consumidores (muy frecuentemente se escuchan voces contrarias).

\section{5.-EL VALOR DE LA RESPONSABILIDAD SOCIAL DE LA EMPRESA (RSE) EN LA MEJORA DE SU IMAGEN PERCIBIDA Y EN LAS ACTITUDES Y COMPORTAMIENTO DEL CONSUMIDOR}

Aunque algunos autores no demuestran la influencia de la RSE en la mejora de la competitividad directamente, sí perciben y demuestran un efecto positivo de la imagen de responsabilidad social en cuestiones que, sin duda, pueden contribuir de manera importante a la mejora de la misma.

Así, algunos afirman que los buenos resultados sociales y medioambientales benefician a la cuenta de resultados, aumentando el valor económico de la empresa (Cuesta et al., 2002); reduciendo el riesgo (Moore, 2001; Orlitzky y

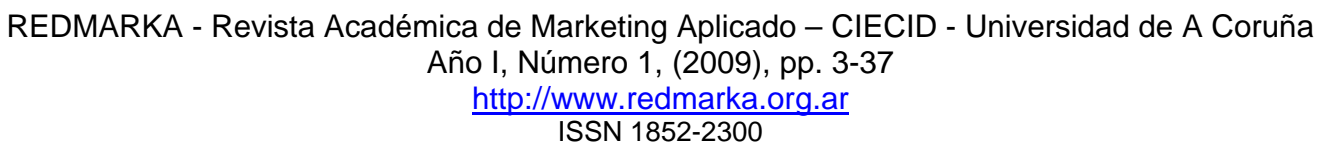


Benjamin, 2001); atrayendo o reteniendo empleados (Backhaus et al., 2002; Turban y Greening, 1997); además, la inversión en RSE hace que la empresa sea más competitiva en licitaciones, en los países donde hay legislación al respecto (De la Cuesta, Valor y Kreisler, 2003).

Como decíamos con anterioridad, muchos afirman también que el reconocimiento de las prácticas de RSE parece tener una influencia positiva sobre su imagen y su reputación, y sobre las actitudes hacia la empresa (Fombrun y Shanley, 1990) lo que, al mismo tiempo, conduce a un incremento de la fidelidad de sus clientes (Maignan et al., 1999; Brown y Dacin, 1997). Otros constatan incluso que puede influir significativamente en el comportamiento del consumidor hacia la empresa (Brown y Dacin, 1997; Creyer y Ross, 1997).

Parece claro que actuar de un modo socialmente responsable puede potenciar la confianza y el sentimiento de afinidad hacia una compañía (Aaker, 1996; Maignan et al., 1999) y que ello puede favorecer la elección y recomendación de la marca (Brown y Dacin, 1997) y potenciar la fidelidad del cliente, vía clave de competitividad en mercados maduros (Sureschandar et al., 2001 y 2002 ; Maignan y Ferrell, 2001; García de los Salmones et al., 2007a, Peterson, 1995).

En estos trabajos, el concepto de RSE se estudia de una manera global, incluyendo aspectos de tan diversa índole como la responsabilidad económica, ética, legal o filantrópica de las empresas (Carroll, 1979; Maignan y Ferrell, 2001; Bigné et al., 2005b).

Sin embargo, muchos afirman que la RSE está lejos de ser el principal criterio dominante en las decisiones de compra del consumidor (Carrigan y Bouldstridge, 2000) y criterios más tradicionales como el precio, la calidad o la conveniencia siguen siendo prioritarios en la elección de marca (Marín y Ruiz,

\footnotetext{
${ }^{6}$ Si bien es cierto que en otros casos, se desestima dicha influencia (Boustridge y Cardigan, 2000; Cardigan y Attalla, 2001).

REDMARKA - Revista Académica de Marketing Aplicado - CIECID - Universidad de A Coruña

Año I, Número 1, (2009), pp. 3-37 
2006). Esto provoca que, a pesar de que los consumidores posean actitudes favorables hacia los comportamientos éticos y sociales de las empresas, en la práctica se produce un gap importante entre su actitud y su comportamiento (Carrigan y Attalla, 2001).

El trabajo de profesionales, académicos e instituciones públicas a partir de aquí deberá ser, por tanto, el de analizar las causas de esta disonancia y plantear posibles soluciones para que la RSC pueda llegar a alcanzar en un futuro una posición relevante en las actuaciones tanto de empresas como de consumidores.

Algunos autores apuntan en este sentido a la importancia del esfuerzo en comunicación de la RSE (Curras, 2007 y Bigné et al 2008) afirmando que sin él no puede lograrse ni siquiera el pretendido cambio de percepciones $\mathrm{y}$, por tanto, de actitudes del público objetivo destinatario de la misma (clientes u otros grupos de interés/stakeholders en general) que ha de ser previo a la consecución de objetivos de marketing más ambiciosos. Nos referimos a objetivos tales como la mejora la imagen de empresa y la lealtad del consumidor hacia la misma, la identificación consumidor-empresa que de forma, como mínimo indirecta, favorece su fidelidad y su preferencia hacia la marca o empresa (Currás, 2007; Bhattacharya y Sen 2003 y 2004) e incluso el aumento de la intención de compra.

En cualquier caso, algunos trabajos son optimistas y demuestran de forma empírica, que los consumidores valoran, e introducen en sus evaluaciones de marcas y productos, consideraciones éticas y sociales hasta el punto de alterar realmente sus comportamientos y patrones de compra y consumo (no solo sus actitudes o motivaciones). Por ejemplo, Creyer y Ross (1997) demuestran que una significativa parte de consumidores están dispuestos a recompensar el comportamiento ético de las empresas mediante el pago de un precio superior por sus productos, $y$, del mismo modo, desean pagar un precio inferior por un producto de una empresa no ética, como forma de penalización. 
Sin embargo, como afirma Currás (2007), otros autores llegan a conclusiones muy diferentes a las anteriores. Por ejemplo, Carrigan y Attalla (2001) realizaron un estudio cualitativo y exploratorio con el propósito de conocer hasta qué punto los consumidores introducen juicios éticos en sus comportamientos de compra en el que concluyen que la sofisticación del consumidor, expresada por autores como Titus y Bradford (1996) y referida a la mayor formación del consumidor y conocimiento de sus derechos y de los requerimientos legales exigibles a los productos, no es condición suficiente para plantear que, de forma generalizada, ello lleva a la introducción de juicios éticos en los comportamientos de compra. Afirman, además, que si bien los consumidores poseen actitudes favorables hacia los comportamientos éticos de las empresas, en la práctica esta actitud no se traduce en comportamiento de compras consecuente.

En este misma línea, se expresan también Vicente y Aguirre (2003) al afirmar que aunque existen evidencias claras de que continúan aumentando las actitudes favorables hacia el medio ambiente (uno de los tres elementos básicos de la RSE), sigue habiendo importantes divergencias entre la actitud general hacia el medio ambiente y el comportamiento de compra.

Por su parte, un estudio de carácter crosscultural sobre la percepción de la RSE en las decisiones de compra de jóvenes consumidores, realizado por Bigné, Chumpitaz, Andreu y Swaen (2005), llega a conclusiones muy similares. Los jóvenes consumidores de España, Portugal, Chile y Argentina, a pesar de mantener actitudes positivas hacia la asunción de responsabilidades sociales por parte de las empresas, utilizan poco la RSE como criterio valorativo en sus decisiones reales de compra de productos. Ante la pregunta de si disponer de información de RSE les es útil para decidir sus compras, con una escala de 1 a 10, los jóvenes respondieron con una media de un escaso 5,8. Además, preguntados por los criterios de compra más utilizados a la hora de comprar dos categorías de productos diferenciados (zapatillas de deporte y desodorantes), la RSE aparece como el cuarto factor en importancia, por detrás de la calidad, el precio, la disponibilidad y la imagen de la empresa. 
Cabe pensar además que los jóvenes tengan en general un espíritu más altruista que las personas mayores y por otra parte que respondieran con cierto sesgo por el efecto "prestigio social" y respuesta políticamente correcta, por lo que la realidad de los comportamientos de compra mayoritarios diste todavía bastante de reflejar una valoración real positiva en el sentido de las conclusiones arrojadas por el citado trabajo de Carrigan y Attalla (2001).

Antes de presentar el planteamiento y los resultados de la parte empírica de este trabajo, solo nos resta añadir que algunas empresas con una clara concienciación en favor de la RSE y que realizan importantes inversiones en pro de la misma, no hacen sin embargo comunicación externa sobre sus esfuerzos de RSE por estar convencidas de que sus clientes no lo entenderían; verían en la misma intereses demasiado mercantilistas y ello iría, por tanto, en detrimento de su imagen, lejos de ir en su beneficio. Sin embargo, muchas de estas empresas afirman que la inversión en RSE y el conocimiento interno de la misma, contribuye de manera muy significativa a la satisfacción, motivación $y$, derivado de ello posiblemente, al mejor desempeño de las personas que trabajan en ellas o que las dirigen. Por esta razón, esas mismas empresas que no hacen esfuerzos de comunicación externa de la RSE, sí los hacen de comunicación interna ${ }^{7}$ y no debemos olvidar que la Web de una empresa y, sobre todo sus recursos de intranet, pueden ser un medio de comunicación interna muy interesante, tanto más cuanto más grande sea la empresa.

\section{SEGUNDA PARTE: TRABAJO EMPÍRICO}

\section{1.-PLANTEAMIENTO DEL TRABAJO}

Como comentábamos en la introducción, con el fin de conocer el esfuerzo que se estaba realizando en nuestro país en acciones de Responsabilidad Social se decidió estudiar su implantación en un conjunto de empresas punteras, eligiendo como tales aquellas presentes en el Foro de Marcas Renombradas Españolas.

\footnotetext{
${ }^{7}$ Este es el caso de la COMPAÑÍA CERVECERA CANARIA, que en una conferencia impartida por uno de sus directivos durante la celebración del XX Encuentro de Profesores Universitarios de marketing celebrado en Septiembre de 2009, expreso está idea textualmente.

REDMARKA - Revista Académica de Marketing Aplicado - CIECID - Universidad de A Coruña Año I, Número 1, (2009), pp. 3-37 
Por todas las razones explicadas en la introducción de este artículo, a la hora de realizar el estudio, y en virtud de las aportaciones de toda la bibliografía consultada y comentada con anterioridad, se partía de la hipótesis de que la Responsabilidad Social de estas empresas fuera mayor que la de la media española y que además podía estar positivamente vinculada con su imagen y con su intención de traspasar las fronteras nacionales.

A ello, se unía también el hecho importante de que se tratara de un universo limitado y totalmente accesible, lo que resultaba un también un objetivo operativo sin duda importante

Para hacer el análisis, se visitaron durante los meses de abril y mayo de 2008 las páginas web de cada una las 80 organizaciones integradas en el Foro y se analizaron en profundidad para encontrar indicios de RSE. En la búsqueda, se trató de identificar todo aquello que pudiera denotar sensibilidad hacia las siguientes cuestiones:

1. Derechos y condiciones laborales

2. Medio ambiente

3. Orientación social en general:

o Colaboración en proyectos de apoyo a personas con discapacidades, u otros grupos de personas desfavorecidas tercera edad, inmigrantes, etc-

o Proyectos de cooperación al desarrollo.

o Proyectos de cooperación y financiación de actividades culturales y deportivas

o Proyectos de ayuda humanitaria

- Apoyo a causas con valor social en general (grupos o colectivos vecinales, colectivos/asociaciones vinculadas a enfermedades de cualquier tipo, etc.)

5. Promoción de la RSE entre sus proveedores, trabajadores y otros grupos de interés

6. Otros indicios como índices de sostenibilidad, poseer una ISO 14000 , premios de RSE, etc... 
Se analizó también el número de clicks necesarios para encontrar el primer indicio de RSE.

A la hora de agrupar las organizaciones, y pese a que en el Foro de Marcas Renombradas españolas hubiera una agrupación sectorial concreta, utilizamos otra diferente para organizar el trabajo en futuras investigaciones. La agrupación que empleamos fue la que presentamos a continuación.

\section{2.-RELACIÓN DE EMPRESAS Y SECTORES OBJETO DEL PRESENTE}

\section{ESTUDIO}

Las empresas se han agrupado en servicios; alimentación y bebidas; textil, calzado, complementos y distribución comercial; ocio; industria manufacturera y construcción. A continuación indicamos las incluidas en cada grupo:

\section{Tabla 1. Listado de empresas analizadas por sectores}

\begin{tabular}{|c|}
\hline A.-SERVICIOS: \\
\hline $\begin{array}{l}\text {-Turísticos: Barceló, Iberia, NH Hoteles, Paradores de España } \\
\text { •Banca, Seguros e Inversiones: BBVA, Grupo Santander, LA CAIXA y MAPFRE } \\
\text { •Servicios públicos/suministros energéticos y generales: Applus+, Gas Natural, Grupo } \\
\text { Agbar, Iberdrola, Renfe, Repsol, Telefónica, Televés } \\
\text { •Escuelas de negocios y Servicios profesionales y a empresas: Cuatrecasas abogados, } \\
\text { EOI Escuela de Organización, ESADE, Garrigues, GMV innovating solutions, IESE, } \\
\text { INSTITUTO DE EMPRESA }\end{array}$ \\
\hline B.-ALIMENTACIÓN Y BEBIDAS \\
\hline $\begin{array}{l}\text {-Alimentación: ACESUR, Chupa Chups, Santiveri, Borges, Coren, Grupo SOS/Cuétara, } \\
\text { Calvo, EI Pozo, Pescanova, Campofrío, Gallo, Nutrexpa/ColaCao } \\
\text {-Bebidas: Codorniu, Grupo Leche Pascual, J. García Carrión/Don Simón, Freixenet, } \\
\text { Osborne, Licor 43, González Byas, Miguel Torres, Marqués de Cáceres/Unión Vitivinícola }\end{array}$ \\
\hline C.-TEXTIL/CALZADO/COMPLEMENTOS Y DISTRIBUCIÓN COMERCIAL \\
\hline $\begin{array}{l}\text { Adolfo Dominguez, Mango, Saez Merino/Lois, Coronel Tapioca, PanamaJack, Pulligan, Grupo } \\
\text { Cortefiel, Pronovias, El Corte Inglés, Inditex, Armand Bassi, Joma Sport, Mirto, Miguel Bellido }\end{array}$ \\
\hline D.-OCIO \\
\hline Atletico de Madrid, F.C. Barcelona, Hola, Real Madrid, Cirsa \\
\hline E.-INDUSTRIA MANUFACTURERA \\
\hline $\begin{array}{l}\text {-Manufacturas Business to Businnes: CAF, IRIZAR, IKUSI, Nicolás Correa, SIMON } \\
\text {-Manufacturas para el Consumo y otras: FAGOR, PUIG, LLADRÓ, RODMAN, Keraben, } \\
\text { Natura Bissé } \\
\text {-Manufacturas sanitarias: INDAS, INDO }\end{array}$ \\
\hline
\end{tabular}

REDMARKA - Revista Académica de Marketing Aplicado - CIECID - Universidad de A Coruña

Año I, Número 1, (2009), pp. 3-37 


\begin{tabular}{l}
-Servicios Conexos a industria: Applus+ \\
F.-CONSTRUCCIÓN \\
\hline Acciona \\
\hline
\end{tabular}

\section{3.- RESULTADOS DEL TRABAJO}

A continuación expondremos los principales resultados de la investigación realizada.

\subsection{1.-Momento en que aparecen los primeros indicios de responsabilidad social}

El primer análisis realizado consistió en detectar cuándo aparecía el primer indicio de acción de responsabilidad social. En un importante número de empresas (33 concretamente) fue en la propia página de inicio; en otras 8 empresas el primer indicio aparecía tras haber hecho un click (generalmente, en información corporativa, empresa, compañía...) y en las webs de 6 empresas fue necesario hacer dos clicks para acceder a dicha información. En el resto de las empresas los indicios aparecían más escondidos o, incluso, no aparecían. En 16 de las páginas no aparecía absolutamente nada (aún cuando, recurriendo a buscadores, en dos de los casos sí había referencias a acciones de RS).

Gráfico 1: Momento de aparición de los primeros indicios de Responsabilidad social

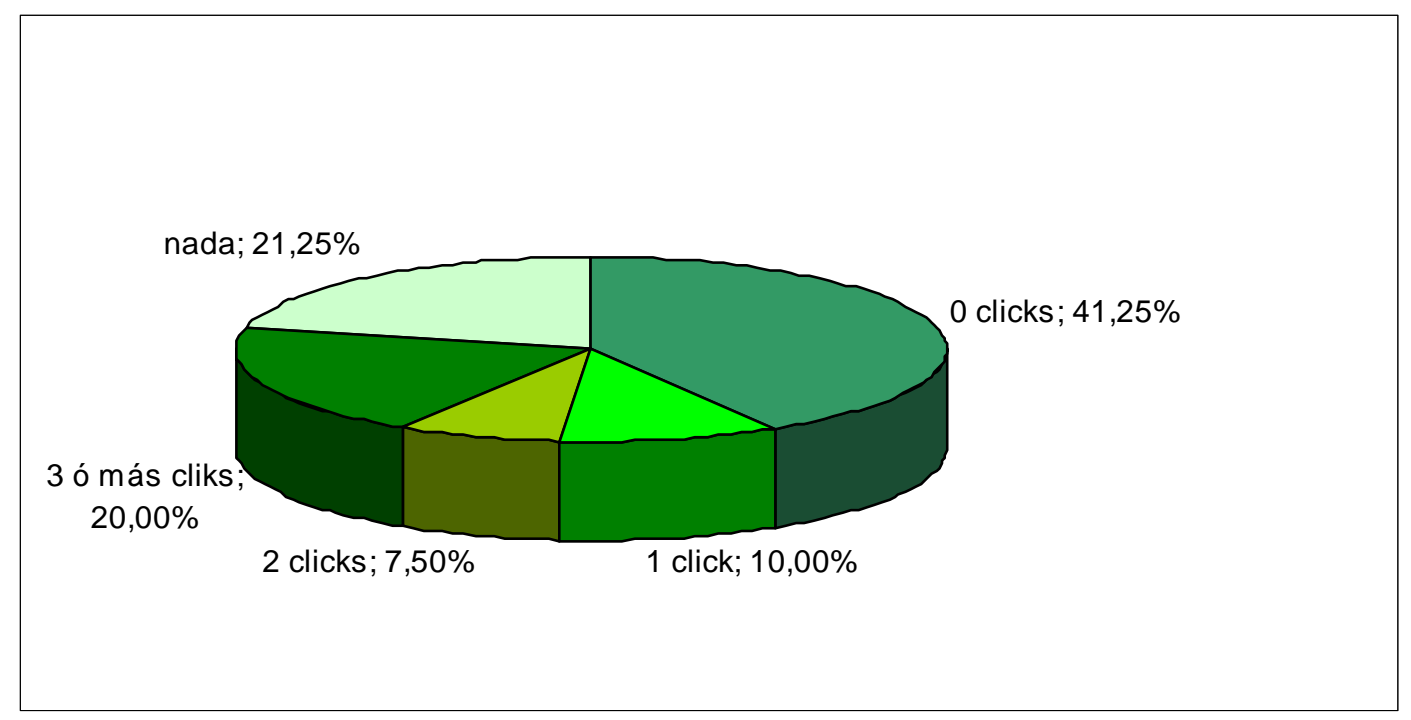

REDMARKA - Revista Académica de Marketing Aplicado - CIECID - Universidad de A Coruña 


\subsection{2.- Adhesión al Pacto Mundial de Naciones Unidas:}

El $47.5 \%$ de las empresas estudiadas están adheridas al Pacto (concretamente 38 de un total de 80). Esta es una cifra muy importante, especialmente teniendo en cuenta que en España, según datos del INE de 2007 (ver informe aquí) existen 90.000 empresas con más de 20 personas asalariadas y que, según datos de ASEPAM (Asociación Española del Pacto Mundial) sólo 652 empresas españolas están adheridas al Pacto, el porcentaje de adhesión al mismo es ínfimo, no superando el $0,7 \%$ en el mejor de los casos.

\subsection{3.-Información acerca de certificaciones ISO 14.001 logradas}

Del colectivo estudiado, un total de 26 empresas especifican en su web poseer una certificación ISO 14.001, lo que supone un $32.5 \%$ del colectivo de empresas estudiadas. Considerando los datos anteriormente comentados (90.000 empresas españolas de más de 20 asalariados) y, que según datos de Aenor (ver informe aquí) en España existían en 2006, 11.125 empresas con esta certificación, tan sólo un 12,36\% del total de las empresas (en el mejor de los casos) tienen esta certificación. Es reseñable comentar que el porcentaje de las empresas del foro que afirman tener la ISO 14.001, es casi el triple del porcentaje a nivel nacional, lo cual ya es significativo, pero más todavía siendo España, como es, es el primer país europeo en número de certificaciones medioambientales.

\subsection{4.-Información acerca de su sensibilidad medioambiental}

De las 80 empresas analizadas, 48 sí muestran, en mayor o menor grado acciones encaminadas a la mejora del medio ambiente /además de la descrita en el epígrafe anterior). A este respecto, conviene recordar que, en 16 de las 80 empresas no aparecía absolutamente nada relacionado con la Responsabilidad Social de la empresa, con lo que, de aquellas en las que aparece alguna acción de RSE, el 75\% menciona el medio ambiente.

Aparte de la implantación de la ISO 14.001, muchas de ellas tienen implantado un sistema de gestión medioambiental, hacen un esfuerzo por reducir sus emisiones de $\mathrm{CO} 2$, envases... 
Al ser las empresas tan diferentes entre sí, el tipo de acciones medioambientales que realizan son también muy diferentes, siendo destacable que, cuanto mayor es el potencial impacto medioambiental propio de su actividad, mayor es el esfuerzo medioambiental reflejado en su web (empresas de sectores con elevado impacto medioambiental, como el energético o el del transporte, hacen un mayor esfuerzo que la media en este tipo de acciones)

Una excepción reseñable a esta regla es la de la empresa Miguel Torres, dedicada a la producción y comercialización de vinos y brandies. En su web aparece una sección específica dedicada a "Torres y Medio Ambiente" y otra denominada "Preservando el Medio Ambiente" donde se dice explícitamente que "no hay buen vino que no respete la naturaleza". Asimismo, a través de su fundación trabajan en proyectos de protección de especies en peligro como el águila perdicera y colaboran con gobiernos regionales en programas de prevención de incendios; ofrecen subvenciones para financiación del 50\% del coste de patrullas de Vigilancia Forestal en Penedés; instalaron plantas fotovoltaicas para ahorro energético; financian proyectos de reforestación, etc.

\subsection{5.- Información acerca de los derechos y condiciones laborales de sus trabadores/as}

Son 42 las empresas que indican algo relacionado con los derechos y condiciones laborales de su personal. Dado que 16 de las empresas no hacían ninguna mención a la RSE en su web, estas 42 empresas suponen el 65.6\% de las empresas que hacen referencia $a$, al menos algún aspecto de su responsabilidad social en su web.

Al igual que sucedía en el caso anterior, el tipo de acciones es muy diverso aún cuando sí se observa que son frecuentes las siguientes acciones: promoción de la no discriminación, igualdad de oportunidades, políticas de conciliación de la vida laboral y familiar, beneficios sociales variados a su personal y, en muchos casos, respeto de determinadas condiciones laborales en todos los países del mundo aún cuando, en algunos de ellos, la normativa no lo exija. Así, por ejemplo, en Adolfo Domínguez la semana de trabajo no supera las 48 horas en ningún país, aún cuando, por normativa local, podría ser superior. 
Otro ejemplo de empresa que comunica muy intensamente su preocupación por los derechos y condiciones de su personal es Iberdrola. En Iberdrola se fomenta la igualdad de oportunidades y no discriminación; la integración de trabajadores con discapacidad con principio de igualdad de trato; beneficios sociales siempre por encima de lo que marca la legislación de los distintos países: seguro de vida; seguro médico; cobertura de invalidez; fondo de pensiones; gratificaciones por antigüedad; ayudas especiales para atender necesidades de hijos y cónyuges; ayudas de estudios para hijos de empleados; ayudas por fallecimiento en accidente de trabajo; anticipos especiales; apartamentos; comedores de empresa; excedencias por maternidad/paternidad y reducciones de jornada... Uno de los frutos de estas acciones fue la obtención, en mayo de 2006, del certificado de Empresa Familiarmente Responsable, otorgado por la Fundación Familia, por su contribución a la conciliación de la vida personal y laboral.

\subsection{6.- Información aparecida acerca de su contribución a acciones de cooperación al desarrollo}

De las empresas del Foro, 40 afirman realizar alguna acción de cooperación al desarrollo, frente a otras 40 que no muestran ningún indicio en su web. En la gran mayoría de los casos, lo hacen apoyando a ONGs que realizan su labor en el Sur. En otras, a través de fundaciones que ellos han creado.

Como ejemplo a resaltar se podría mencionar Barceló que lo hace tanto a través de su propia Fundación, como de ONGs. El objetivo de su Fundación es llevar a cabo proyectos que incidan no sólo en la ayuda a los más necesitados en un momento determinado, sino que logren en los beneficiarios una rampa de lanzamiento para seguir desarrollando su actividad de un modo cada vez más autosuficiente y eficaz en el futuro, colaborando con ello al desarrollo económico y social de las zonas donde residen. Desarrolla su labor en países como Ecuador (proyecto de microcréditos para 150 mujeres), Nicaragua (proyecto para la renovación del cultivo de piña en Ticuantepe), Níger (microcréditos para mujeres de la región de Diffa) y República Dominicana (apoyo a la creación de microempresas). Asimismo, para poder brindar una asistencia médica y sanitaria gratuita a las poblaciones más necesitadas y 
desasistidas de los países de Centroamérica y Caribe, la Fundación Barceló creó en 1995 el Programa de Ayuda Médica Internacional. Empezaron las actividades en la República Dominicana y año a año se han ido incorporando nuevos países y nuevos centros, extendiendo los beneficios del programa a muchas más personas (Guatemala, Nicaragua, Costa Rica, República Dominicana, Kenia y Honduras). También ha realizado proyectos de mejora de las condiciones personas con el VIH-SIDA, en los barrios marginales de Puerto Príncipe y ha colaborado en la dotación de equipamiento de diagnóstico para el Hospital de Kanzenze (R.D. del Congo).

Con respecto a las acciones que Barceló realiza a través de ONGs, se pueden destacar su colaboración en el Bosque de Juigalpán (Nicaragua) donde, desde principios del año 2005, su Fundación colabora con Paz y Tercer Mundo y con Afodenic en un proyecto consistente en la construcción de 498 casas en esa zona. Otra ONG con la que colaboran, esta vez en Ecuador es Viviendas Hogar de Cristo con la que, desde hace unos años, construyen viviendas dignas, con la participación directa de los beneficiarios en su construcción. Otro proyecto con el que ha colaborado es el programa de letrinización en el departamento de Managua (Nicaragua), atendiendo a uno de los objetivos primordiales en el campo de la salud como es la mejora de las condiciones sanitarias e higiénicas de aquellas zonas identificadas que no disponen de los servicios mínimos necesarios.

\subsection{7.-Información acerca de actividades culturales y deportivas que financian}

De las empresas del Foro, 37 afirman realizar alguna actividad cultural y/o deportiva, frente a 43 que no muestran ningún indicio en su web. Dentro de las actividades culturales, estas empresas financian, entre otras al siguiente tipo de entidades: Universidades, Museos, Organizaciones vinculadas a la Música, así como proyectos para familiarizar a determinados públicos en el uso de las TICs. En cuanto a las actividades deportivas, financian tanto a deportistas, equipos y acontecimientos de élite, como Fernando Alonso, el Real Madrid, la liga de Fútbol como a equipos locales mucho más pequeños que pretenden potenciar el deporte de base. 
Como ejemplo de empresa que destaca en la financiación de actividades culturales y deportivas, estaría RENFE. En su compromiso con la cultura tienen cabida numerosas actividades, especialmente las que cuentan con un vínculo especial con el mundo del ferrocarril. Así, durante el año 2007, algunas de las acciones que realizó fueron la entrega de 60.000 libros entre los viajeros el día del libro, 23 de abril (estos libros eran una recopilación de los cuentos y poemas de los ganadores de la pasada edición de los "Premios del Tren"). Con la misma finalidad de promoción de la lectura, colabora con la Feria del Libro de Sevilla 2007, clasificada como la tercera en España en su género. Para facilitar el acceso de las personas a la cultura, colabora con diversos museos como el Museo del Prado, el Teatro Real de Madrid, el Teatro de la Maestranza y Salas del Arenal de Sevilla, el Real Alcazar de Sevilla y el Teatro para Niños del Museo del Ferrocarril de Madrid. Patrocina asimismo el Festival Internacional de Titirimundi, uno de los festivales de teatro de títeres con carácter anual más reconocidos y prestigiosos del mundo para mantener una tradición cultural de siglos en España. Además, fomenta las artes plásticas con una exposición de dibujo infantil y juvenil bajo el título "El tren en el Mediterráneo", con obras de estudiantes de primaria y secundaria en la Comunidad Valenciana. Finalmente, dentro de las actividades deportivas, Renfe es patrocinador oficial de la Selección Española de Balonmano y de Rugby, en todas sus categorías, tanto masculinas como femeninas y patrocina asimismo la Copa de España de Fútbol Sala Trofeo Renfe.

\subsection{8.-Información reflejada acerca reproyectos de ayuda humanitaria}

En este caso, son tan sólo 12 las empresas que afirman colaborar en casos de emergencia humanitaria, aunque es posible que haya algunas más que lo hacen pero no lo explicitan o la incluyen dentro de su cooperación al desarrollo. En este caso, la mayor parte de las acciones consisten en la cesión de dinero para paliar los efectos de las emergencias humanitarias allí donde se producen a través de ONGs especializadas en este tipo de acciones. El dinero destinado en 9 de las 12 empresas suele ser una partida de sus beneficios, en otra (Grupo SOS/Cuétara) donan producto en especie y. en las otras dos: Armand Bassi y Coronel Tapiocca, no hacen donaciones directas sino que donan los 
beneficios de ropa diseñada específicamente para estos casos de forma que es la población la que se involucra comprando dichos productos y estas empresas se encargan de entregar los beneficios a las ONGs con las que colaboran. Así, Armand Bassi destinó el beneficio íntegro de la venta de camisetas estampadas con dibujos de niños afectados por la catástrofe del tsunami asiático a Unicef y Coronel Tapiocca diseñó una línea de camisetas cuya recaudación fue destinada a MSF. Lo cierto es que las acciones de estas dos últimas empresas, aunque sí dan muestra de una actitud socialmente responsable, técnicamente son más acciones de marketing con causa que de RSE.

\subsection{9.-Información acerca de su apoyo a personas desfavorecidas}

En este ámbito, son 35 las empresas que afirman realizar al menos una acción con personas desfavorecidas. Estas acciones las realizan en ocasiones, directamente, en otras a través de las Fundaciones que ellos mismos han creado y, también, a través de diversas ONGs. Entre los colectivos beneficiados por estas acciones, se encuentran las personas con discapacidad física y psíquica, con síndrome de Down, con enfermedades terminales u otro tipo de enfermedades como cáncer, cardiopatías diversas, autismo o diabetes. También hay acciones destinadas a infancia sin familia, mujeres víctimas de violencia de género, prostitutas, condenados a pena de muerte en Estados Unidos, ex-drogodependientes... La colaboración de las empresas en la gran mayoría de los casos es económica pero en otros, consiste en ofrecer empleo a personas de estos grupos, en crear programas específicos como las ciberaulas de La Caixa en hospitales; las donaciones en especie como Chupa Chups a la Asociación Española contra el Cáncer para facilitar que la gente deje de fumar o donaciones en conocimientos y tiempo como el programa de Esade en el que los estudiantes de derecho trabajan en la defensa de los condenados a muerte sin recursos económicos de Houston (EE.UU).

Como ejemplos de colaboración económica y de empleo, se puede destacar la empresa Acciona. Esta empresa colabora con la ONCE contratando a personas con discapacidad, siendo el número de los que preveía contratar en 
2007, de 150. Es además significativo que ACCIONA pretenda pasar del $2 \%$ de personas con discapacidad en su plantilla establecido por ley al 3\% en los próximos cuatro años. También apoya económicamente a la Asociación Española de Lucha contra el Cáncer, a la Fundación Síndrome de Down y a la Fundación INTEGRA en la integración laboral de personas pertenecientes a colectivos marginales.

\subsubsection{0.-Otras acciones de RSE}

Aquí se han incluido todas las acciones que no tenían cabida en los epígrafes anteriores tales como acciones para fomentar una alimentación sana y equilibrada, transmisión de conocimientos de gestión en facultades donde se imparte Administración y Dirección de Empresas, donaciones a asociaciones de ayuda en carretera, proyectos locales... En total, han sido 18 las empresas que tenían alguna acción que se pudiera englobar en esta categoría.

Un ejemplo de empresa que desarrolla lo que hemos denominado "Otras acciones de RSE" es Inditex que colabora con dos proyectos locales y otro de alcance mucho mayor. Por una parte, con la Fundación Galicia Emigración, para el desarrollo de iniciativas relacionadas con la migración en Galicia y, por otra, en un proyecto para paliar el impacto socioeconómico del hundimiento del petrolero Prestige frente a las costas gallegas. El proyecto de mayor alcance que realiza es la colaboración en un proyecto encaminado a financiar las actividades del centro nacional de investigaciones cardiovasculares.

\subsubsection{1.-Promoción de la RSE entre sus proveedores, trabajadores y otros grupos de interés}

En el análisis de esta importante labor, se observa que 38 empresas del foro hacen algún esfuerzo de promoción de la RSE si bien es muy frecuente que no promuevan la RSE en general, sino tan sólo la responsabilidad medioambiental. Los públicos entre los que promueven la RSE son, con un papel muy destacado, su propio personal y sus proveedores, siendo frecuente que a éstos últimos, no sólo se les exija un determinado comportamiento medioambiental, sino también de respeto de los derechos humanos (factor éste especialmente importante cuando los proveedores son de países menos 
desarrollados). Otro destinatario habitual, aunque en menor medida que los anteriores, de la promoción de la RS es la sociedad en general.

Una empresa a destacar en este aspecto es Mango que firmó en 2006 un convenio con la Escuela Superior de Comercio Internacional perteneciente a la Pompeu Fabra, a través del cual se creó la Cátedra MANGO de RSC, cuyo objetivo consiste en fomentar la investigación en diversas áreas de RSC a nivel internacional. Además de esta herramienta de difusión e investigación sobre RSC, exigen a sus proveedores el cumplimiento del mismo código ético que Mango con su propio personal con lo que, claramente, contribuyen a la difusión de la RSE ante la sociedad en su conjunto, por medio de la cátedra y también ante sus proveedores al exigirles el cumplimiento del código ético.

\subsubsection{2.-Indices de sostenibilidad}

Un factor que indica su esfuerzo de sostenibilidad es la pertenencia a índices de sostenibilidad. En este sentido, se puede destacar que cinco de las empresas del Foro (Gas Natural, Iberia, Iberdrola, Repsol y Telefónica) están incluidas en el prestigioso Índice de Sostenibilidad del Dow Jones y, dos de ellas (Repsol e Iberdrola), además, lo están en el Climate Leadership Index.

\subsubsection{3.-Mención en la web a premios obtenidos por acciones de RSE}

Un total de 19 de las empresas analizadas afirman en sus webs haber tenido algún tipo de premio a sus acciones de Responsabilidad Social. Las entidades que otorgan estos premios son tanto ONGs, como organismos públicos, revistas, etc. Un ejemplo de empresa muy premiada sería el grupo $\underline{\text { SOS }}$ Cuétara que recibió el Premio Empresa y Sociedad 2007 en su modalidad de Desarrollo Comunitario por su actuación en el entorno de la fábrica de Túnez y en México a través de la Fundación Fesmai. También recibió el $X$ premio Codespa 2006 a la empresa solidaria por su ayuda a más de 2.600 niñas y niños desfavorecidos de Latinoamérica a través de la Fundación Fesmai y por las medidas puestas en marcha en su fábrica de Túnez. Asimismo, fue galardonada por el Ayuntamiento de Alcobendas con el premio Deporte 2006 en la categoría de Mejor Patrocinador Deportivo. 


\subsubsection{4.-Otros aspectos destacables}

El último aspecto que nos parece reseñable destacar es que quince de las empresas del Foro mencionan explícitamente en su web tener constituida una Fundación con el mismo nombre que la empresa en todos los casos excepto en el de El Corte Inglés, donde la fundación se llama Ramón Areces en honor al fundador de la cadena de grandes almacenes.

\subsection{5.-Cuadro Resumen de los indicios de RSE}

A continuación, presentamos un cuadro resumen de los indicios que hemos encontrado en las webs de las 80 empresas analizadas. Por una parte, presentamos el dato del número de empresas con referencia a los distintos aspectos analizados y, posteriormente, calculamos este dato en porcentaje sobre el total de empresas del foro. Al observar esta columna, ya se constata que el porcentaje de acciones que realizan en materia de RSE es importante. No obstante, para aislar aún más el efecto de las 16 empresas que no destacan nada, hemos decidido calcular también el porcentaje sobre las 64 en cuyas webs hay indicios de realizar alguna acción de RSE (última columna9.

\begin{tabular}{|c|c|c|c|}
\hline Cuadro resumen de indicios de RSE & $\begin{array}{l}N^{\circ} \text { de empresas con } \\
\text { referencia a este } \\
\text { aspecto en su web }\end{array}$ & $\begin{array}{c}\text { Porcentaje } \\
\text { sobre el total } \\
\text { del foro }\end{array}$ & $\begin{array}{c}\text { Porcentaje sobre } \\
\text { empresas que sí } \\
\text { destacan algo }\end{array}$ \\
\hline Existencia de indicios en la web & 64 & 80,00 & 100,00 \\
\hline Adhesión al Pacto Mundial & 38 & 47,50 & 59,38 \\
\hline Certificación ISO 14.001 & 26 & 32,50 & 40,63 \\
\hline Sensibilidad hacia el Medio Ambiente & 48 & 60,00 & 75,00 \\
\hline Derechos y Condiciones Laborales & 42 & 52,50 & 65,63 \\
\hline Cooperación al Desarrollo & 40 & 50,00 & 62,50 \\
\hline Actividades Culturales y Deportivas & 37 & 46,25 & 57,81 \\
\hline Ayuda Humanitaria & 12 & 15,00 & 18,75 \\
\hline Apoyo a personas desfavorecidas & 35 & 43,75 & 54,69 \\
\hline Otras aaciones de interés social & 18 & 22,50 & 28,13 \\
\hline Promoción de la RSE en su entorno & 38 & 47,50 & 59,38 \\
\hline Premios recibidos por acciones RSE & 19 & 23,75 & 29,69 \\
\hline
\end{tabular}




\begin{tabular}{|l|l|l|l|}
\hline Empresas con Fundación propia & 15 & 18,75 & 23,44 \\
\hline
\end{tabular}

Finalmente, comentar que es destacable que algunas empresas invierten en acciones de RSE de gran valor social y, al mismo tiempo, muy vinculadas con el objeto principal de sus negocios. Nosotros entendemos que este tipo de esfuerzos son especialmente eficaces y eficientes en el cumplimiento de objetivos sociales porque la empresa actúa en un campo que domina y, además, pueden ser eficaces en el cumplimiento de objetivos empresariales. Al lograr objetivos empresariales, es posible que las empresas entiendan más interesante su inversión en RSE, lo que a su vez, les puede animar a realizar mayores esfuerzos. Se trataría, por tanto, de una especie de "círculo virtuoso".

Como ejemplos de empresas del colectivo estudiado que realizan este tipo de acciones tenemos a Indas, empresa dedicada a la fabricación de productos sanitarios e higiénicos como pañales para adultos con problemas de incontinencia y que envían este material a hospitales y ambulatorios de Malawi. Otro ejemplo sería el de lberia que cede las bodegas de sus aviones para el transporte de ayuda humanitaria o el de $\mathrm{NH}$ hoteles que ceden gratuitamente dos habitaciones en un hotel de Madrid a permanente disposición de familias que las necesitan para intervenciones y tratamiento de los niños afectados por cardiopatías congénitas. En esta misma línea, Keraben, empresa fabricante de productos cerámicos, fabricó azulejos y baldosas diseñadas por los niños del del Hospital General de Valencia, donando todo el material necesario para la reforma de las consultas externas de pediatría. Finalmente, también se podría destacar la acción de Indo, empresa fabricante de gafas que distribuye gratuitamente gafas nuevas y usadas entre grupos de personas desfavorecidas.

\section{TERCERA PARTE: CONCLUSIONES}

A continuación presentamos las principales conclusiones del estudio realizado.

Primera: El 47,5\% de las empresas del Foro de Marcas Renombradas, explicitan en la web su adhesión al Pacto Mundial de Naciones Unidas, lo cual indica la importancia que, para estas empresas, tiene el cumplimiento de los

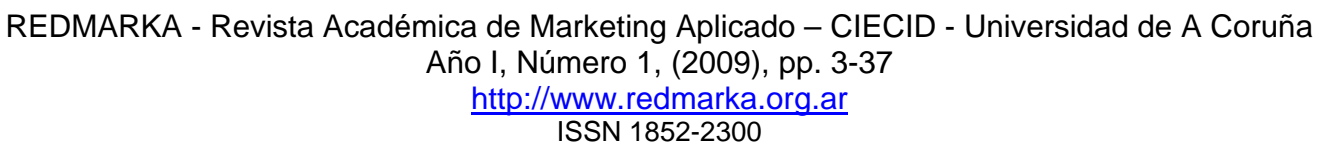


principios de dicho Pacto y que recogen la esencia de la RSE. Con respecto a la ISO 14.001, el porcentaje, aunque no tan alto, 32,5\%, es también importante. Estos porcentajes superan muy ampliamente los registrados para la totalidad de empresas españolas que, en el mejor de los casos, son del $0.7 \%$ de adhesiones al Pacto Mundial y 12,36\% de certificaciones ISO 14.001 .

Segunda: La mayoría de las empresas estudiadas dan a conocer a través de sus páginas web sus esfuerzos a favor del medio ambiente. De hecho, cuando hablan de RSE, el $60 \%$ se refiere a este aspecto.

El esfuerzo medioambiental por parte de las empresas tiende a ser directamente proporcional al impacto medioambiental de su actividad, siendo las compañías energéticas las que más invierten en medio ambiente.

Tercera: Además de acciones en material medioambiental, las empresas del Foro invierten en otro amplio y variado abanico de acciones de RSE. Así, se observa que el tipo de acciones preferidas por un mayor número de empresas son (de mayor a menor): aquéllas relacionadas con los derechos y condiciones laborales de su personal, cooperación al desarrollo, promoción de la RSE, actividades culturales y deportivas y apoyo a personas desfavorecidas. Es destacable que más del $40 \%$ de las empresas del foro indican en sus webs realizar acciones en alguna o varias de estas materias.

Cuarta: Algunas de las acciones de RSE que realizan estas empresas tienen también un componente comunicacional importante, especialmente las relacionadas con promoción cultural y deportiva.

Quinta: Algunas empresas invierten en acciones de gran valor social y, al mismo tiempo, muy vinculadas con el objeto principal de su negocio lo que, resulta doblemente interesante. Este tipo de esfuerzos pueden ser especialmente eficaces y eficientes en el cumplimiento de objetivos sociales porque la empresa actúa en un campo que domina $y$, además, en el cumplimiento de objetivos empresariales. Al lograr objetivos empresariales, es posible que las empresas entiendan más interesante su inversión en RSE, lo que a su vez, les puede animar a realizar mayores esfuerzos. Se trataría, por tanto, de un "círculo virtuoso".

\section{CUARTA PARTE: LIMITACIONES DEL TRABAJO}


Este trabajo adolece de limitaciones que será conveniente ir superando en trabajos de investigación posteriores. Entre las limitaciones, podemos destacar:

a.- El colectivo de empresas estudiado es muy heterogéneo en sectores, tipo actividad y tamaño empresa, pero ningún sector está debidamente representado, ni ningún tamaño, ni región, por lo que las conclusiones obtenidas son difícilmente extrapolables a otros colectivos empresariales diferentes al estudiado..

b.- No hay comparativa, ni estudio de causalidad alguno. Es decir, es un trabajo meramente descriptivo y no hemos indagado acerca de las diferentes razones por las que las empresas hacen este tipo de esfuerzos, ni acerca de los posibles "rendimientos" derivados de los mismos, si es que los hubiera, etc.

c.- Tampoco hemos indagado acerca de los porcentajes de inversión en RSE, lo que sería un buen dato acerca del esfuerzo relativo real de estas empresas. Podría ser interesante también realizar una comparativa por sectores, tipos de empresas, etc.

\section{BIBLIOGRAFÍA}

AAKER, D (1996): "Construir marcas poderosas". Ed. Gestión 2000

AAKER, D. (1996): "Measuring Brand Equity Across Products and Markets". California Management Review, 38, 3, 102-121.

ARAQUE, R. A. Y MONTERO, M. J. (2006), La responsabilidad social de la empresa a debate, Icaria Editorial, Barcelona.

BACKHAUS, K.B.; STONE, B.A. AND HEINER, K. (2002): "Exploring the Relationship Between Corporate Social Performance and Employer Attractiveness" Business \& Society, Vol. 41, No. 3, pp. 292-318

BHATTACHARYA, C.B. y SEN, S. (2003): "Consumer-company identification". Journal of Marketing 67 (2), págs.76-88

BHATTACHARYA, C.B. Y SEN, S. (2004). "Doing better at doing good: when, why, and how consumers respond to corporate social initiatives", California Management Review, Vol. 47, $\mathrm{n}^{\circ}$ 1, pgs. 9-24. 
BIGNÉ, E.; CURRAS, R; ALVARADO, A.; ALDAS, J. (2008): "Influencia de las asociaciones de responsabilidad social corporativa en el valor percibido y en la satisfacción cognitiva y afectiva del consumidor" XX Encuentro de Profesores Universitarios de Marketing. Libro de actas, pág. 235. Maspalomas, Gran Canaria

BIGNÉ, LA; CHUMPITAZ, Y y SWAEN V., (2006): "La influencia de la Responsabilidad Social corporativa en el comportamiento de compra de estudiantes universitarios". ESIC Market, Vol. 6, nº 597, pgs. 163-189.

BIGNÉ, E., CHUMPITAZ, R., SWAEN V., ANDREU, L. (2005): "Percepción de la RSC. Un análisis cross-cultural”. Universia Business Review (5), págs. 14-27

BIGNÉ, LA; CHUMPITAZ, Y; SWAEN V., ANDREU, L, (2003): "Being a socially responsible company: what does it mean for european young consumers?, Proceedings of the $32^{a}$ European Marketing Academy Conference, Glasgow: University of Strathclyde

BOWEN, HR (1953): Social Responsabilities of the businessman. New York. Harper \& Row.

BROWN, TJ. Y DACIN, PA. (1997): "The company and the product: Corporate associations and consumer product responses". Journal of Marketing Vol 61, nº1, págs. 68-84

CABEZA, L; MARTÍNEZ A; FUENTES E (2007): "La obra social en las cajas de ahorros de castilla y león: un estudio de su evolución y efecto en el resultado empresarial". XXI Congreso Anual AEDEM, Universidad Rey Juan Carlos, Madrid, 6,7 y 8 de junio de 2007

CARRIGAN, M. y ATALLA, A (2001): "The myth of the ethical consumer-do ethics matter in purchase behavior?" Journal of consumer marketing Vol. 18, nº 7 , págs.560-578

CARRIGAN Y BOULSTRIDGE (2000): "Do consumers really care about corporate responsibility? Highlighting the attitude-behaviour gap". Journal of Communication Management, Vol.4, nº4. Págs 355-368

CARROLL, A.B. (1999). "Corporate social responsibility: evolution of a definitional construct". Business \& Society, Vol. 38, $n^{\circ} 3$, pgs. 268-295..

CHAUDHURI, A. y HOLBROOK, M. B. (2001): "The Chain of Effects from Brabd Trust and Brand Affect to Brand Performance: the Role of Brand Loyalty", Journal of Marketing, April, Vol. 65, nº 2, pp. 81-94.

COMISIÓN EUROPEA. (2001). Libro verde: fomentar un marco europeo para la responsabilidad social de las empresas. Bruselas: Comisión de las Comunidades Europeas. 
CREYER, MH. Y ROSS WTJ (1997): "The influence of firm behavior of purchase intention: do consumers really care about business ethics?" The Journal of consumer marketing Vol.14, n6, pp 421-432 CUESTA, M de la (2004): "El porqué de la responsabilidad social corporativa" Boletín Económico de ICE, Vol. 2813,2 de agosto, Madrid

CUESTA, M de la y VALOR, C. (2003). "Responsabilidad social de la empresa. Concepto, medición y desarrollo en España". Boletín Económico de ICE, Vol. 2755, pp. 7-19.

CUESTA, M de la, VALOR, C, BOTIJA, M y SANMARTÍN, S (2002): "La RSC: una aplicación en España".Economistas sin fronteras, UNED, Madrid

CUESTA, M de la, VALOR, C, BOTIJA, M y SANMARTÍN, S (2002): Inversiones éticas en empresas socialmente responsables" Economistas sin fronteras, UNED, Madrid

CUESTA, M de la, VALOR, C. y KREISLER I. (2003): "Integración de la responsabilidad social de la empresa en el cuerpo legislativo español" Economistas, $X X I$, pp.219-223

CUESTA, M de la, VALOR, C. y KREISLER I. (2003): "Promoción institucional de la Responsabilidad Social Corporativa: iniciativas internacionales y nacionales" Boletín Económico, ICE. Información Comercial española, Sep 2228, pp. 9-20

CURRÁS, R. (2007). Comunicación de la responsabilidad social corporativa: imagen e identificación con la empresa como antecedentes del comportamiento del consumidor. Tesis Doctoral, Universitat de València, Valencia.

CSR Europe; MORI (2000): The first ever European survey of consumers' attitudes towards

corporate social responsibility. CSR Europe, Bruselas.[www.csreurope.org]

DAVID, P., KLINE, S. Y DAI, Y. (2005). "Corporate social responsibility practices, corporate identity, and purchase intention: a dual-process model". Journal of Public Relations Research, Vol. 17, n 3, pgs. 291-313.

DIAZ de la HOZ, J. (2008): "Del progreso imposible al futuro sostenible. Modelos empresariales para la Sostenibilidad" Ponencia presentada el día 8 de septiembre de 2008 en Santander dentro de los Cursos de Verano de la Universidad Internacional Menéndez Pelayo. Colgado en: http://www.eoi.es/nw/Multimedia/salaprensa/08-0909 encuentrouimp ponencia jdiazdelahoz pwc.pdf

DODDS, W. B., MONROE, K. B. Y GREWAL, D. (1991). "Effects of price, brand, and store information on buyers'product evaluations". Journal of Marketing Research, Vol. 28, nº 3, pgs. 307-319. 
DOWLING, G.R. (1986): "Managing Your Corporate Images", Industrial Marketing Management, vol. 15, pp. 109-15

DOWLING, G.R. (1988), "Measuring corporate images: a review of alternative approaches", Journal of Business Research, Vol. 17 No.1, pp.27-34.

ECCLES, R.G.; HERZ, R.H.; KEEGAN, E.M.; PHILLIPS, D. (2001). La Revolución VALUEREPORTING. Más allá de la cuenta de resultados. PriceWaterhouseCoopers, Ediciones Deusto, Barcelona

FOMBRUN, CJ. Y SHANLEY, M. (1990): "What's in a name? Reputation building and corporate strategy". The academy of management journal Vol33, n०2, pp. 233-258

FREEMAN, R.E. (1984): Strategic Management: A stakeholder approach" Pitman-Ballinger, Boston

FUNDACIÓN EMPRESA Y SOCIEDAD (1999): Marketing con causa: Cómo añadir valor a las marcas vinculándolas a proyectos sociales, Madrid, Fundación Empresa y Sociedad.

GALLARZA, M.G. y GIL, I. (2006). "Value dimensions, perceived value, satisfaction and loyalty: an investigation of university students' travel behaviour". Tourism Management, Vol. 27, nº 3, pgs. 437-452.

GRACIA PERDIGUERO., t. (2003): La Responsabilidad social de las empresas en un mundo global. Ed Anagrama, Barcelona.

GARCÍA DE LOS SALMONES, M.D.M., RODRÍGUEZ DEL BOSQUE, I. Y SAN MARTíN, H. (2007). "The corporate social responsibility as a marketing tool: influence on consumer behaviour in services sector". Paper presentado en International Congress Marketing Trends, París.

GARCÍA DE LOS SALMONES, MM y RODRÍGUEZ DEL BOSQUE, I. (2005):"Estudio de los determinantes de la imagen corporativa: una aplicación empírica en mercado de la telefonía móvil", Revista europea de Dirección y Economía de Empresa, vol. 15, $\mathrm{n}^{\circ} 4$ (2006). Pp 121-140. Universidad de Cantabria

GARCÍA DE LOS SALMONES, M.D.M., HERRERO, Á. Y RODRÍGUEZ DEL BOSQUE, I. (2005). "Influence of corporate social responsibility on loyalty and valuation of services". Journal of Business Ethics, Vol. 61, n 4, pgs. 369-385.

GUTHEY, E., MORSING, M. AND LANGER, R. (2006): "La responsibilidad social corporativa como moda de gestión empresarial". Harvard Deusto Business Review, no. 150, October, pp. 56-67, 2006

HALL, R. (1993): "A framework linking intangible resources and capabilities to sustainable competitive advantage". Strategic Management Journal. Vol14 n8, pp. 607-618

REDMARKA - Revista Académica de Marketing Aplicado - CIECID - Universidad de A Coruña 
IGLESIAS, S; CALVO, A; LOPEZ, V (2003): "Una aproximación empírica al concepto de reputación". Gestión científica empresarial: temas de investigación actuales, 2003

IGLESIAS, S, CALVO, A, LÓPEZ, V Y LÉVY, JP (2004): "Análisis del concepto de reputación y de su relación con el rendimiento empresarial". Ciencia Ergo Sum, Nov. 2003-Feb. 2004. Vol 10, núm 3. Pp. 245-253

LUO, X. Y BHATTACHARYA, C.B. (2006). "Corporate social responsibility, customer satisfaction, and market value", Journal of marketing, Vol. $70, \mathrm{n}^{\circ} 4$, pgs. 1-18.

LOZANO, J (1999): Etica y empresa. Trotta 1999

MAIGNAN, I., FERRELL, O. Y HULT, G.T.M. (1999). "Corporate citizenship: cultural antecedents and business benefits". Journal of The Academy of Marketing Science, Vol. 27, $n^{\circ}$ 4, pgs. 455-469.

MAIGNAN, I (2001): "Antecedents and benefits of corporate Citizenship: An investigation of French Business", Journal of Business Research. Vol. 51, pp 37-51

MAIGNAN, I. y FERRELL, O.C. (2001): "Corporate citizenship as a marketing instrument". European Journal of Marketing 35 (3/4), 457-484

MAIGNAN, I. y FERRELL, O.C. (2003). "Nature of corporate responsibilities: perspectives from American, French, and German consumers". Journal of Business Research, Vol. 56, $n^{\circ}$ 1, pgs. 55-67.

MAIGNAN, I, FERRELL, OC, (2004): "Corporate Social Responsability: An integrative framework", Journal of the academy of market science, Vol. 32, pp 3-19

MAIGNAN, I., FERRELL, O.C. Y FERRELL, L. (2005). "A stakeholder model for implementing social responsibility in marketing". European Journal of Marketing, Vol. 39, no 9-10, pgs. 956- 977

MARÍN, I; RUIZ, C (2006): "Producto inseguro y product defectuoso". Revista para el análisis del derecho. $\mathrm{N}^{\circ} 4$

MCWILLIAMS, A., SIEGEL, D.S. Y WRIGHT, P.M. (2006). "Corporate social responsibility: international perspectives". Journal of Business Strategies, Vol. $23, n^{\circ} 1$, pgs. 1-12.

MOHR, L.A. Y WEBB, D.J. (2005). "The effects of corporate social responsibility and price on consumer responses". Journal of Consumer Affairs, Vol. 39, $\mathrm{n}^{\circ} 1$, pgs. 121-147. 
MOORE, G.(2001): "Corporate Social and Financial Performance: An Investigation in the U.K. Supermarket Industry" Journal of Business Ethics. Volume 34, Numbers 3-4, pp.299-315

MORI (2000): "European attitudes towards corporate citizenship". Corporate social responsability update 2 . www.mori.com

MORENO IZQUIERDO, J.A. (2004): "Responsabilidad Social Corporativa y Competitividad: una visión desde la empresa" Revista Valenciana de Economía y Hacienda, $\mathrm{n}^{\circ} 12$, pp. 9-50.

NIETO, M y FERNANDEZ, R (2004): "RSC; la última innovación en management", Universia Business Review- Actualidad económica, Vol 1, pp2839

ORLITZKY, M and BENJAMIN, J.D. (2001): "Corporate Social Performance and Firm Risk: A Meta-Analytic" Review" Business \& Society, Vol. 40, No. 4, pp. 369-396

ORLITZKY, M., SCHMIDT, F. and RYNES, S. (2003). "Corporate social and financial performance: A meta-analysis." Organization Studies, 24, PP. 403-44. Puede encontrarse

en: http://business.auckland.ac.nz/newstaffnet/profile/publications upload/0000005 56 orlitzkyschmidtrynes2003os.pdf

PETERSON, R.A. (1995) "Relationship marketing and the consumer". Journal of The Academy of Marketing Science, Vol. 23, no 4, pgs. 278-281.

PORTER, M.E. Y KRAMER, M.R. (2002). "The competitive advantage of corporate philanthropy". Harvard Business Review, Vol. 80, n 12, pgs. 56-68.

PRICEWATERHOUSECOOOPERS (2003): Responsabilidad Social Corporativa: tendencias empresariales en España. Editado por PWC, Madrid

PRICEWATERHOUSECOOOPERS (2001): La Revolución Value Reporting. Más allá de la cuenta de resultados. Ediciones Deusto, Barcelona

RAMOS, E., PUEYO, R., LLARÍA, J. (2004): "Las organizaciones de la sociedad civil y la responsabilidad social corporativa. Algunos casos destacables" Colección "La empresa de mañana", Elaborado por Fundación Ecología y $\quad$ Desarrollo. En http://www.ecodes.org/documentos/archivo/Ecodes OSC y RSC 2004.pdf

RAMOS, J; PERIAÑEZ, I (2003): "Delimitación del Marketing con Causa o Marketing Social Corporativo mediante el análisis de empresas que realizan acciones de responsabilidad social". Cuadernos de gestión, Vol 3, n 1-2, pp$65-82$

RODRIGUEZ DEL BOSQUE, I (1995): "La comunicación de la imagen de la empresa". Alta Dirección, Año nº 30, № 181, 1995, pags. 79-91

REDMARKA - Revista Académica de Marketing Aplicado - CIECID - Universidad de A Coruña 
SURESCHCHANDAR, G.S., RAJENDRAN, C. y ANANTHARAMAN, R.N. (2002): "The Relationship Between Service Quality and Customer Satisfaction A factor Specific Approach", The Journal of Services Marketing, Vol. 16, $\mathrm{n}^{\circ} 4$, pp. 363-379.

SURESHCHANDAR, G., RAJENDRAN, C. Y KAMALANABHAN, T. (2001). "Customer perceptions of service quality: a critique". Total Quality Management, Vol. 12, n 1, pp. 111124.

SWAEN, V. (2003). Consumers' perceptions, evaluations and reactions to CSR activities. Working paper 2003-mar-7. IESEG Working Papers.

TITUS, P.A. AND BRADFORD, J.L. (1996), "Reflections on consumer sophistication and its impact on ethical business practice", Journal of Consumer Affairs, Vol. 30 No. 1, pp. 170-94.

TURBAN, D. B. Y GREENING, D.W. (1997): "Corporate Social Performance and Organizational Attractiveness to Prospective Employees", Academy of Management Journal, Vol. 40, pp. 658-672.

TURNBULL, P.W. (1986): "The Image and Reputation of British Suppliers in Western Europe", European Journal of Marketing, vol. 19, núm. 6, pp. 9-52.

TRUÑÓ, J. (2006): La responsabilidad social corporativa en la gestión empresarial. Universidad Autónoma de Barcelona

VAN MARREWIJK, M. (2003). "Concepts and definitions of CSR and corporate sustainability: between agency and comunion". Journal of Business Ethics, Vol. $44, n^{\circ} 2-3$, pgs. 95-105.

VICENTE, A. y AGUIRRE, M.S. (2003): "Factores psicológicos determinantes del comportamiento ecológico: una aproximación a través de la evidencia empírica" Esic Market. № 114; enero-abril 2003. pp.201-222

VILLAFAÑE, J (1999): La gestión profesional de la imagen corporativa. Ediciones Pirámide, Madrid

Para citar este artículo:

Aguirre García, María Soledad - Aldamiz-echevarría, Covadonga - Baelo, Luis M $^{\mathrm{a}}$ (25-022009). EL ESFUERZO EN RESPONSABILIDAD SOCIAL Y SU COMUNICACIÓN EN INTERNET: EL CASO DE LAS EMPRESAS DEL FORO DE MARCAS RENOMBRADAS ESPAÑOLAS.

REDMARKA - CIECID - Unidad de Investigación en Marketing Aplicado-Universidad de A Coruña

Año I, Número 1, VI, pp.3-37

ISSN 1852-2300

URL del Documento : http://www.cienciared.com.ar/ra/doc.php?n=1000

REDMARKA - Revista Académica de Marketing Aplicado - CIECID - Universidad de A Coruña Año I, Número 1, (2009), pp. 3-37 http://www.redmarka.org.ar

$$
\text { ISSN 1852-2300 }
$$

